\title{
Nitric Oxide and Infection: Another View
}

\author{
G. Schoedon, M. Schneemann, R. Walter, N. Blau, \\ S. Hofer, and A. Schaffner
}

\author{
From the Division of Infectious Diseases, Clinical Mycology \\ Laboratory, Department of Medicine, University of Zürich Medical \\ School, Zürich, Switzerland
}

\begin{abstract}
Nitric oxide (NO) has been nicknamed "murderer" and "mediator" because it has toxic and signaling properties. We review these two aspects of NO synthesis from the perspective of the clinical infectious disease specialist by considering the potential of NO as an endothelium-derived relaxing factor (EDRF) in inflammation and sepsis and its potential as an antimicrobial system. We deviate from observations in recent authoritative reviews and point to important species differences that make it unlikely that NO serves as an EDRF mediating inflammatory vasodilatation in humans or that NO synthesized by human phagocytes has an antimicrobial function. We propose that in humans, NO synthesis is more confined and compartmentalized than in certain other animal species, and therefore, unwelcome toxicity, vasodilatation, or disturbance of paracrine signaling mechanisms (i.e., modulation of phagocytic cell functions) are avoided during inflammation.
\end{abstract}

Nitric oxide (NO) has received much attention over the last few years and was named molecule of the year in 1992 [1]. The recent scientific literature is replete with articles on the many aspects of biological and pathological processes involving NO (reviewed in [2-4]), suggesting at times that NO might be a jack-of-all-trades. Two aspects of the generation of NO are of particular interest to infectious disease specialists: (1) the potential role of NO as a cytotoxic molecule contributing to the antimicrobial armature of phagocytes and (2) the role of NO as a vasodilator of inflammation and mediator of septic shock. We outline our view on the role of NO in infectious processes in the human system. Our view deviates in some aspects from recent authoritative analyses [2-4] and takes into account evolutionary adaptations favorable to a utilization of this highly reactive and toxic molecule, nicknamed "murderer' [3], as a mediator.

NO is produced in human and laboratory animals by NO synthases (NOS). NOS isoenzymes [5] have been categorized into inducible and constitutive isoforms (table 1). However, it is apparent that activity of inducible NOS (iNOS) is also constitutively present in many tissues, and that a constitutively present activity of iNOS is further upregulated by enzymeinducing signals in these cell types [6-8]. It has also become clear that the expression and activity of the constitutive NOS (cNOS) are modulated as well [9].

\section{NO as Antimicrobial Product of Mononuclear Phagocytes}

NO derived in mononuclear phagocytes by a high-output iNOS from L-arginine has been proposed to have antibacterial,

Reprints or correspondence: Dr. A. Schaffner, Clinical Mycology Laboratory, Division of Infectious Diseases, Department of Medicine, University Hospital, CH-8091 Zürich, Switzerland.

Clinical Infectious Diseases 1995;21(Suppl 2):S152-7 1995 by The University of Chicago. All rights reserved. 1058-4838/95/2104-0003\$02.00 antifungal, and antiprotozoal activity [2-4]. In animal macrophages, notably murine macrophages, the pathway of NO synthesis and its regulation have been well characterized (reviewed in [10]). This includes consumption of the substrates $L$-arginine and $\mathrm{O}_{2}$, production of the co-product L-citrulline, and the need of cofactors reduced nicotinamide adenine dinucleotide phosphate (NADPH), flavin adenine dinucleotide (FAD), and tetrahydrobiopterin $\left(\mathrm{BH}_{4}\right)$. Most studies regarding the role of NO formation, including its role as an antimicrobial product, depend on quantitation of nitrite, an oxidation product formed spontaneously from NO in biological systems. The main reason for this is that nitrite can be measured by a convenient and technically simple test that can be performed in any laboratory. However, there are many potential pitfalls in correlating nitrite concentrations to NO production (figure 1, table 2). Artificial accumulation of nitrite by an unknown mechanism occurs in culture media incubated for 7 or more days without ever changing the medium. Nitrite formation is independent of the type of medium, the presence of living cells, or the presence of chemicals like sodium azide, and is significantly higher in the presence of IL-4. In media incubated at room temperature without $\mathrm{CO}_{2}$, nitrite forms even more readily (our unpublished observation).

To demonstrate convincingly the production of $\mathrm{NO}$, it is necessary either to use cumbersome assays measuring NO by chemoluminescence or to show that L-arginine is converted into L-citrulline along with nitrite production [11]. To date there is no convincing evidence that human phagocytes produce NO in amounts that could account for antimicrobial activity. Most, if not all, of the discrepancies in the scientific literature in regard to NO production by human phagocytes ensue from the confinement of these studies to the measuring of nitrite in biological systems. In addition, as of this writing no single laboratory has reported (based on stringent biochemical methods) that human phagocytes dispose of high-output NOS activity. Studies depending on L-arginine analogues used as "inhibitors"' have also not been helpful in establishing a role for NOS 
Table 1. Tissue distribution of nitric oxide synthases in animal models.

\begin{tabular}{|c|c|c|}
\hline $\begin{array}{l}\text { Cellular source } \\
\text { and } \\
\text { activator(s) }\end{array}$ & cNOS & iNOS \\
\hline Cellular source & $\begin{array}{l}\text { Endothelium* } \\
\text { Neurons* } \\
\text { Epithelial cells* } \\
\text { Astrocytes* } \\
\text { Neutrophils } \\
\text { Thrombocytes }^{\ddagger}\end{array}$ & $\begin{array}{l}\text { Endothelium }^{\dagger} \\
\text { Hepatocytes* } \\
\text { Macrophages }^{\dagger} \\
\text { Smooth muscle cells* } \\
\text { Carcinoma cell lines* } \\
\text { Neutrophils } \\
\text { Islet cells } \\
\text { Mesangium cells* } \\
\text { Cardiomyocytes }{ }^{\dagger} \\
\text { Fibroblasts } \\
\text { Bronchial epithelium* }\end{array}$ \\
\hline Activators & $\begin{array}{l}\text { Calcium ionophore } \\
\text { Excitatory amino acids } \\
\text { Acetylcholine, bradykinin }\end{array}$ & $\begin{array}{l}\text { IFN- } \gamma \text {, LPS, in combinations: } \\
\text { TNF- } \alpha, \text { IL- } 1, \text { IFN- } \alpha\end{array}$ \\
\hline
\end{tabular}

NOTE. cNOS $=$ constitutive nitric oxide synthase; iNOS $=$ inducible nitric oxide synthase; LPS = lipopolysaccharide.

* In animal and human cells.

${ }^{\dagger}$ In animal but not in human cells.

${ }^{\ddagger}$ Not defined in human cells.

as a killing system of human phagocytes. In such experiments, complex biological systems such as macrophages and target cells were exposed for prolonged times to these amino acid analogues; no appropriate control experiments were performed. In particular, the potential effects of these antimetabolites on protein synthesis of phagocytes or target cells and, above all, an effect on the growth phase of microorganisms that critically affects susceptibility to killing [12] were not addressed in such studies.

On the basis of these reflections, it cannot be overemphasized that, in contrast with animal studies [10] or studies on human hepatocytes [13], scientists have failed to demonstrate, by biochemical methods other than mere nitrite measurement, highoutput iNOS activity in human mononuclear phagocytes, including tissue macrophages and microglia $[11,14,15]$, as well as in neutrophils [16]. Another basic issue related to this is the fact that there are fundamental biochemical differences between human mononuclear phagocytes and phagocytes from certain animal species. Human mononuclear phagocytes lack relevant arginase or urea cycle activity, and therefore, they do not metabolize L-arginine by this pathway $[8,11]$. It has also been shown that human mononuclear phagocytes lack the enzyme systems required for the synthesis of the $\mathrm{BH}_{4}$, an essential cofactor required for NO synthesis (table 3 ). It should be incidentally noted that exogenous $\mathrm{BH}_{4}$ can not support NO synthesis in human macrophages [11].

iNOS has been cloned, and the regulation of its expression has been studied in human, murine, and rat mononuclear phagocytes by northern analysis, which permitted quantitative assess- ment of specific cellular mRNA levels. While lipopolysaccharide (LPS) and IFN- $\gamma$ were able to induce within hours longlasting synthesis of iNOS mRNA in phagocytes from rats and mice, no iNOS mRNA was detectable by this method in stimulated and unstimulated human phagocytes [6]. When a much more sensitive reverse-transcriptase PCR (RT-PCR) method was used, minute amounts of iNOS mRNA were transiently detected upon stimulation with LPS/IFN- $\gamma$ in human peripheral blood mononuclear cells that had been purified of monocytes (but nevertheless contained 1\%-2\% contaminating cells of other types). It is noteworthy that no NOS activity was detectable in these experiments. The minute amounts of iNOS mRNA detected cannot be weighed against amounts found in mononuclear phagocytes from mice or rats [6]. In-depth studies of this phenomenon indicate that minute amounts of iNOS message can be detected by RT-PCR in apoptotic human mononuclear phagocytes, but that this message is not translated into a functional NOS enzyme $[17,18]$. These observations confirm by molecular methods the results of antecedent biochemical studies: human mononuclear phagocytes do not transcribe or translate iNOS message at a level that could be compared with that in phagocytes from mice or rats. Genomic analyses that so far show similarities in the promoter regions of the rodent and human iNOS gene, particularly in respect to IFN- $\gamma$ and LPSdependent regions, cannot explain these important species differences $[19,20]$. The similarities in LPS and IFN- $\gamma$-dependent promoter regions of the NOS gene in humans and mice also speak somewhat against the requirement for occult cytokine

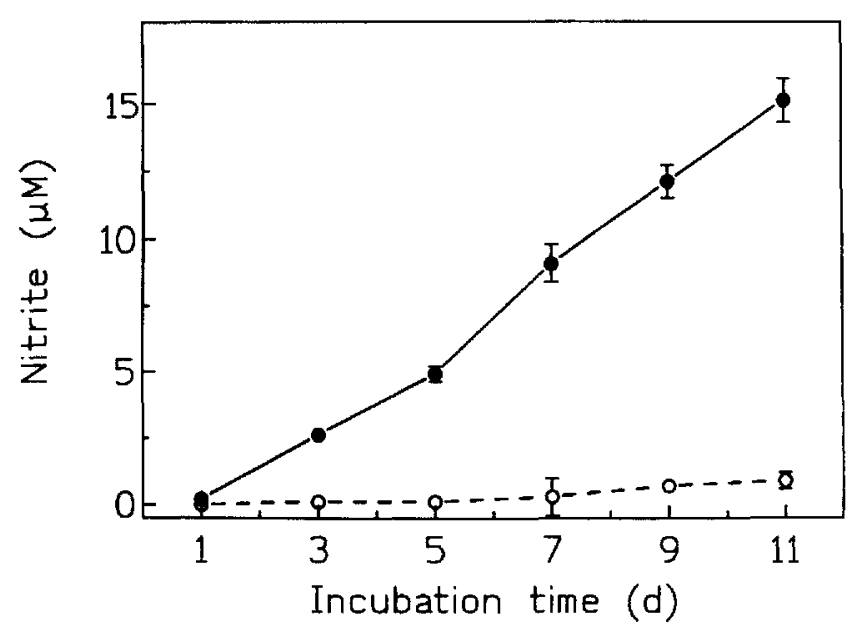

Figure 1. Spontaneous formation of nitrite in cell culture medium (RPMI 1640) supplemented with 5\% fetal bovine serum, human recombinant $\mathrm{IL}-4(200 \mathrm{U} / \mathrm{mL})$, and human recombinant IFN- $\gamma(500 \mathrm{U} /$ $\mathrm{mL}$ ). Cell-free medium was incubated (without changing) at $37^{\circ} \mathrm{C}$, $5 \% \mathrm{CO}_{2}$ for the times indicated $(\bullet)$. In the absence of IL-4/IFN- $\gamma$, nitrite accumulation was minimal $(O)$. This reproducible phenomenon was also seen with other cell culture media supplemented accordingly. None of the supplements contained sodium azide. Nitrite concentration $=$ mean \pm SD from triplicate wells. Medium with and without supplements, $P<.01$ for all values $\geq 3$ days of incubation (Student's $t$-test). 
Table 2. Postulated pathways for nitric oxide production and appropriate experimental assessment.

\begin{tabular}{lc}
\hline \multicolumn{1}{c}{ Pathway } & Experimental assay \\
\hline $\begin{array}{l}\text { Nitrite formed spontaneously in } \\
\text { cell-free medium }\end{array}$ & $\begin{array}{c}\text { Set up cell-free controls accordingly with identical supplements } \\
\text { to media; measure L-citrulline production. } \\
\text { Nitrite formed by ROIs } \\
\text { Use phagocytes defective in ROI generation; use ROI } \\
\text { inhibitors; measure L-citrulline; use substrate analogues for } \\
\text { control. }\end{array}$ \\
$\begin{array}{l}\text { Measure L-citrulline; control for metabolically active } \\
\text { oxidases or microbial nitric oxide } \\
\text { synthase }\end{array}$ & microorganisms. \\
$\begin{array}{l}\text { Nitrite formed by tumor cell target } \\
\text { in cytotoxicity experiments with } \\
\text { macrophages }\end{array}$ & Use target cells without nitric oxide synthase that can be \\
Undesired antimetabolic effects of & induced during coculture by cytokines released from \\
L-arginine analogues & macrophages. \\
& Do not depend on analogues; use substrate antagonist only \\
briefly during killing; check for effects on protein synthesis & and other cell functions of phagocytes and target cells. \\
\hline
\end{tabular}

NOTE. $\quad$ ROI $=$ reactive oxygen intermediate.

Table 3. Metabolic differences between murine and human macrophages concerning the L-arginine/ nitric oxide pathway.

\begin{tabular}{lll}
\hline Parameter & \multicolumn{1}{c}{ Murine macrophages } & Human macrophages \\
\hline L-arginine consumption & $600-800 \mu \mathrm{mol} / 10^{6} \mathrm{cells}$ & $10-20 \mu \mathrm{mol} / 10^{6} \mathrm{cells}$ \\
Arginase activity & Yes & No \\
Ornithine production & $500-700 \mu \mathrm{mol} / 10^{6} \mathrm{cells}$ & $<0.1 \mu \mathrm{mol} / 10^{6} \mathrm{cells}$ \\
Urea production & $800-1,100 \mu \mathrm{mol} / 10^{6} \mathrm{cells}$ & $<0.1 \mu \mathrm{mol} / 10^{6} \mathrm{cells}$ \\
Nitric oxide synthase activity & $\left.1.4-2.2 \mu \mathrm{mol} / \mathrm{h} \cdot 10^{6}\right) \mathrm{cells}$ & $<0.3 \mu \mathrm{mol} /\left(\mathrm{h} \cdot 10^{6}\right) \mathrm{cells}$ \\
Citrulline production & $60 \mu \mathrm{mol} / 10^{6} \mathrm{cells}$ & $<0.1 \mu \mathrm{mol} / 10^{6} \mathrm{cells}$ \\
Cytosolic $\mathrm{BH}_{4}$ & $10-90 \mathrm{pmol} / \mathrm{mg}$ protein & $<0.03 \mathrm{pmol} / \mathrm{mg}$ protein \\
\hline
\end{tabular}

NOTE. Table was adapted from references $[8,11] . \mathrm{BH}_{4}=$ tetrahydrobiopterin.

brews that would instruct viable human macrophages to express iNOS, a concept recommended by those unwilling to accept the undeniable species differences.

Taken together, these findings show that observations made on the role of iNOS in the antimicrobial or antitumoral function of phagocytes from mice, rats, or other species can not be simply transferred to human biology. To date, there is no indication that an inducible high-output NOS is antimicrobially operative in human phagocytes (or, incidentally, in rabbit macrophages) [11].

We have previously proposed that one reason for these species differences might be redundancy of phagocytic killing systems that would allow for species variability [11]. Because species differences regarding L-arginine metabolism of phagocytes are not restricted to iNOS but include arginase and other enzymes of the urea cycle (table 3 ), these disparities must perhaps be seen in a broader context that includes other metabolic pathways. Finally, the question occurs as to whether it was advantageous, in an evolutionary sense, to limit the synthesis of NO, which might not only have antimicrobial functions but could also become injurious to the host, mediating disastrous host responses such as vasodilatation during septic shock.

\section{The Role of NO in Inflammatory Vasodilatation}

In view of the major species differences in the regulation and expression of iNOS in phagocytes, the question arises as to whether comparable differences exist in NOSs of blood vessels. The role of NO in the control of the vascular tone has recently been extensively reviewed [2-4]. There is solid evidence that $\mathrm{NO}$ is an endothelium-derived relaxing factor (EDRF) mediating physiological vasodilatation in animals and humans. In addition, vasodilatation during pathological states such as sepsis and inflammation appears to be mediated by a nitrovasodilator system. In several animal species, iNOS activity is induced by inflammatory mediators in endothelial cells, an activity that is comparable to that of the high-output iNOS in murine macrophages [2]. It is therefore conceivable that NO also plays an important role as an inflammatory EDRF in these species [2-4]. Comparable to observations made in macrophages, however, no high-output iNOS activity can be induced in human endothelial cells by LPS, IFN- $\gamma$, TNF- $\alpha$, or IL-1 $[21,22]$, mediators that induce high-output NOS activity in macrophages and endothelial cells from rats, mice, and cattle or in human hepatocytes [13]. Furthermore, cNOS activity de- 


\section{Human}

\section{Constitutive NOS}

\section{Mouse, Rat}
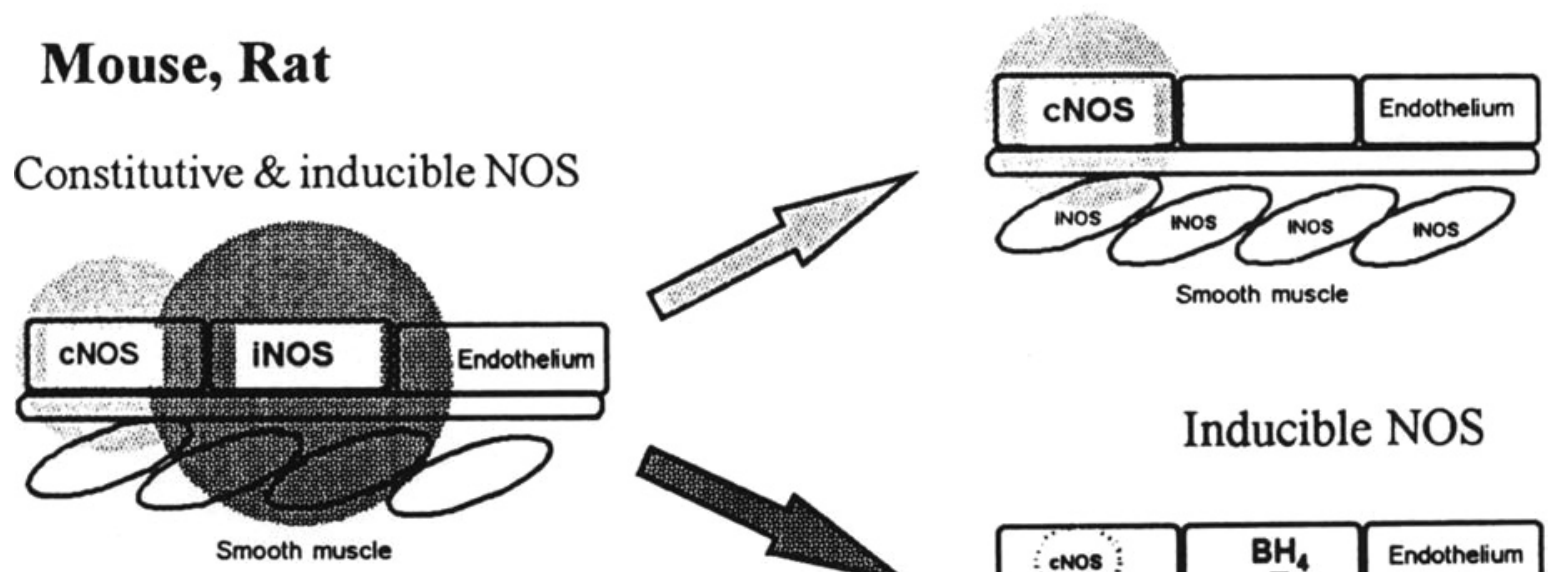

\section{Inducible NOS}
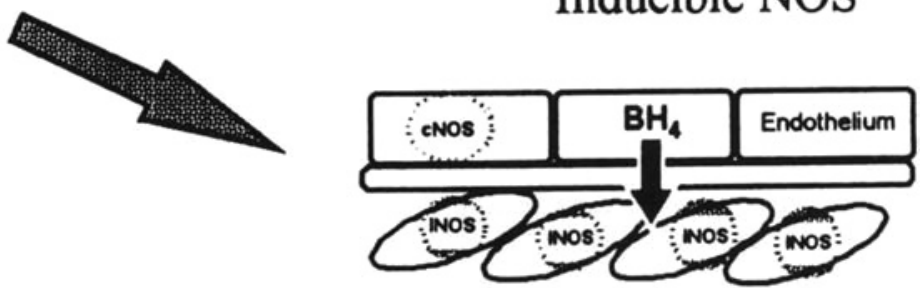

Smooth muscle

Figure 2. Evolutionary compartmentalization of vascular nitric oxide (NO) synthesis. In mice and rats, endothelial inducible nitric oxide synthase (iNOS) present along with the constitutive enzyme (cNOS) has the potential to secrete NO in amounts comparable to toxic amounts produced by rodent macrophages. In contrast, by compartmentalization of NO synthesis in the human vascular system into constitutive endothelial cell (physiological, light gray arrow) and inducible smooth muscle cell (inflammatory, dark gray arrow) isoenzymes, the secretion of large amounts of potentially toxic and randomly diffusing NO synthesized during inflammatory response can be avoided. We propose that endothelial cells regulate $\mathrm{NO}$ synthesis in smooth muscle cells through tetrahydrobiopterin $\left(\mathrm{BH}_{4}\right)$ to conserve inflammatory endotheliumderived relaxing factor function through the nitrovasodilator system, Shaded areas: correspond to random NO diffusion.

creases in endothelial cells under the influence of inflammatory stimuli, and mRNA for cNOS accordingly decreases after exposure to IFN- $\gamma$ and/or LPS without de novo expression of iNOS mRNA in human endothelial cells [21]. Therefore, NO, in contrast to its role in physiology, appears not to be an endothelial mediator (EDRF) of inflammatory vasodilatation in the human system. The question then arises as to where the production of NO occurs that is responsible for the inflammatory vasodilatation attributed to the nitrovasodilator system in humans. Because inflammatory mediators induce iNOS mRNA synthesis in human vascular smooth muscle cells (SMCs), it appears plausible that inflammatory vasodilatation is prompted in humans by NO synthesized within the SMCs themselves. NO activates soluble cytosolic guanylate cyclase in SMCs, resulting in an increase of the intracellular cyclic guanosine monophosphate (cGMP) level, which in turn mediates muscle relaxation [23, 24]. Synthesis of NO at the very site of its action within SMCs appears advantageous over a more distant synthesis in endothelial cells. This advantage might be particularly important in relation to inflammatory vasodilatation caused by high-output iNOS, which is apt to produce large amounts of NO. Randomly diffusing NO produced by an endo- thelial iNOS could lead to considerable tissue damage (figure 2).

All observations made in human cell systems point out that NO is not the inflammatory EDRF. How then is vasodilatation controlled under inflammatory conditions? As mentioned earlier, inflammatory stimuli such as LPS and IFN- $\gamma$ induce synthesis of iNOS in vascular SMCs, but endothelial factors must also be considered for the regulation of inflammatory vasodilatation. We have recently shown that $\mathrm{BH}_{4}$, an obligatory cofactor of NOS, is a highly regulated secretory product of human endothelial cells [25]. In cell culture experiments, exogenous $\mathrm{BH}_{4}$ has been found to have regulatory effects on $\mathrm{NO}$ synthesis and to augment iNOS activity as a limiting factor $[8,23]$. Upon inflammatory stimuli, $\mathrm{BH}_{4}$ synthesis precedes an increase in iNOS activity by several hours. In addition, simultaneous inhibition of $\mathrm{BH}_{4}$ synthesis prevents increased iNOS activity [26]. In isolated rat aorta it has been shown that $\mathrm{BH}_{4}$ induces a marked and long-lasting vasodilatation [27]. These findings made us consider the possibility that $\mathrm{BH}_{4}$ is an EDRF mediating inflammatory vasodilatation in the human vascular system. $\mathrm{BH}_{4}$ secretion by human endothelial cells is markedly regulated by a factor of 70 by activating and deactivating cytokines [25]. 


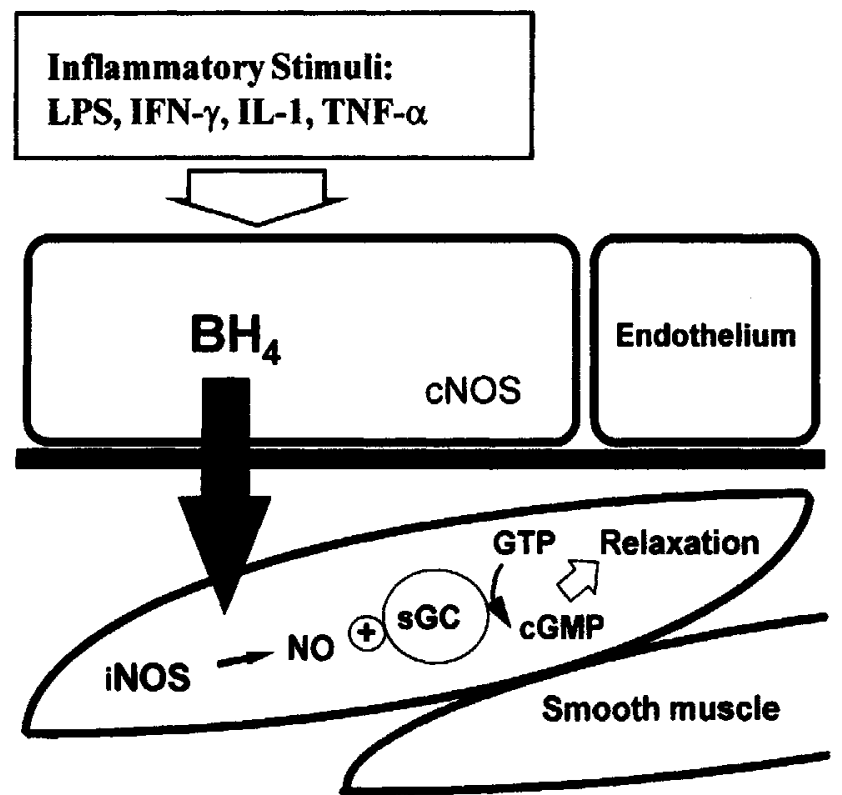

Figure 3. Proposal for regulation of nitric oxide (NO) synthesis in smooth muscle cells (SMCs) by endothelial tetrahydrobiopterin $\left(\mathrm{BH}_{4}\right)$ functioning as an endothelium-derived relaxing factor. While inflammatory stimuli downregulate the expression of constitutive NO synthase (cNOS) in human vascular endothelial cells, they concomitantly induce in these cells the synthesis and vectorial secretion of $\mathrm{BH}_{4}$ in the direction of SMCs. In parallel, inflammatory stimuli upregulate expression of inducible NO synthase (iNOS) in human vascular SMCs. $\mathrm{BH}_{4}$ is a limiting factor for NO synthesis by iNOS in inflammatory stimulated SMCs. Endothelium-derived $\mathrm{BH}_{4}$ acts as first messenger modulating NO production in the SMCs, which as second messenger activates soluble guanylate cyclase (sGC) to synthesize cyclic guanosine monophosphate (cGMP), which mediates relaxation as third messenger.

In addition, endothelial cells secrete $\mathrm{BH}_{4}$ vectorially into the direction of vascular SMCs [23]. Furthermore, we found that intraarterial infusion of $\mathrm{BH}_{4}$ results in a local vasodilatation that is accompanied by local consumption of L-arginine and production of cGMP [23], strong indications that $\mathrm{BH}_{4}$ can act as a mediator of vasodilatation through the nitrovasodilator pathway. In this way, $\mathrm{BH}_{4}$ acts as first messenger controlling NO production in SMCs, which as second messenger controls the synthesis of cGMP, which regulates vasodilatation as third messenger. Based on these observations we propose that not $\mathrm{NO}$ but $\mathrm{BH}_{4}$ is an EDRF in the human vascular system inducing inflammatory vasodilatation (figure 3 ).

These details are of interest because $\mathrm{BH}_{4}$ synthesis is amenable to pharmacological interventions that are aimed at reducing inflammatory vasodilatation. Accordingly, inhibition of $\mathrm{BH}_{4}$ synthesis by coumarins in murine endothelial cells results in a reduction of NO synthesis [26]. Furthermore, there are indications that coumarins can protect animals from experimental septic shock by decreasing NO synthesis [28]. This approach does not necessarily affect the regulation of the vascular tone by NO synthesized by endothelial cNOS under physiological conditions. In septic shock, however, the selective inhibition of $\mathrm{BH}_{4}$ synthesis might be advantageous over a global inhibition of NO synthesis by L-arginine analogues affecting both iNOS and cNOS, which has a detrimental outcome in a canine model of septic shock [29].

\section{Conclusions and Possible Significance of Evolutionary Variations in the Tissue Localization of iNOS}

In conclusion, we propose that NO synthesis in humans is more restricted than in other mammalian species such as the rat and mouse and that not all human tissues dispose of iNOS activity. In humans, prevention of an unhindered redundant expression of iNOS in phagocytes circumvents undesired vasodilatatory signaling and toxic effects. Accordingly, compartmentalization of iNOS activity in human vessel walls with restriction of NO synthesis to SMCs during inflammation could be advantageous because it would avoid autotoxicity of NO. Furthermore, restricted compartmentalized NO synthesis may permit, even during inflammation, paracrine signaling that modulates phagocyte functions [30]. Taken together, the two observations on iNOS in human phagocytes and the vascular system could be viewed as an evolutionary refinement in the use of this intriguing molecule, which can be both a murderer and an essential mediator of biological responses.

\section{References}

1. Koshland DE Jr. The molecule of the year [editorial]. Science 1992;258:1861.

2. Moncada S, Higgs A. The L-arginine-nitric oxide pathway. N Engl J Med 1993; 329:2002-12.

3. Anggard E. Nitric oxide: mediator, murderer, and medicine. Lancet 1994; 343:1199-1206.

4. Vallance P, Collier J. Biology and clinical relevance of nitric oxide. BMJ 1994; 309:453-7.

5. Nathan C. Nitric oxide as a secretory product of mammalian cells. FASEB J 1992; 6:3051-64.

6. Chesrown SE, Monnier J, Visner G, Nick HS. Regulation of inducible nitric oxide synthase mRNA levels by LPS, INF- $\gamma$, TGF- $\beta$, and IL-10 in murine macrophage cell lines and rat peritoneal macrophages. Biochem Biophys Res Commun 1994; 200:126-34.

7. Bernhardt J, Tschudi MR, Dohi Y, Gut I, Urwyler B, Bühler FR, Lüscher TF. Release of nitric oxide from human vascular smooth muscle cells. Biochem Biophys Res Commun 1991; 180:907-12.

8. Schoedon G, Schneemann M, Hofer S, Guerrero L, Blau N, Schaffner A. Regulation of the L-arginine-dependent and tetrahydrobiopterin-dependent biosynthesis of nitric oxide in murine macrophages. Eur J Biochem 1993; $213: 833-9$.

9. Rosenkranz-Weiss P, Sessa WC, Milstien S, Kaufman S, Watson CA, Pober JS. Regulation of nitric oxide synthesis by proinflammatory cytokines in human umbilical vein endothelial cells. Elevations in tetrahydrobiopterin levels enhance endothelial nitric oxide synthase specific activity. J Clin Invest 1994;93:2236-43.

10. Nathan CF, Hibbs JB Jr. Role of nitric oxide synthesis in macrophage antimicrobial activity. Curr Opin Immunol 1991;3:65-70.

11. Schneemann M, Schoedon G, Hofer S, Blau N, Guerrero L, Schaffner A. Nitric oxide synthase is not a constituent of the antimicrobial armature of human mononuclear phagocytes. J Infect Dis 1993; 167:1358-63. 
12. Lehrer RI, Ganz T, Szklarek D, Selsted ME. Modulation of the in vitro candidacidal activity of human neutrophil defensins by target cell metabolism and divalent cations. J Clin Invest 1988;81:1829-35.

13. Geller DA, Nussler AK, Di Silvio M, et al. Cytokines, endotoxin, and glucocorticoids regulate the expression of inducible nitric oxide synthase in hepatocytes. Proc Natl Acad Sci USA 1993;90:522-6.

14. Cameron ML, Granger DL, Weinberg JB, Kozumbo WJ, Koren HS. Human alveolar and peritoneal macrophages mediate fungistasis independently of L-arginine oxidation to nitrite or nitrate. Am Rev Respir Dis 1990; 142:1313-9.

15. Peterson PK, Hu S, Anderson WR, Chao CC. Nitric oxide production and neurotoxicity mediated by activated microglia from human versus mouse brain. J Infect Dis 1994;170:457-60.

16. Yan L, Vandivier RW, Suffredini AF, Danner RL. Human polymorphonuclear leukocytes lack detectable nitric oxide synthase activity. J Immunol 1994; 153:1825-34.

17. Kolb-Bachofen V, Alsdorf K, Fehsel K. Expression of inducible NO synthase mRNA in human monocytes [abstract no. OVIII]. In: The Macrophage, Proceedings of the Eighth Annual Conference of the European Macrophage Study Group. Lausanne, Switzerland; 1994:57.

18. Reiling N, Ulmer AJ, Duchrow M, Ernst M, Flad HD, Hauschildt S. Nitric oxide synthase: $m R N A$ expression of different isoforms in human monocytes/macrophages. Eur J Immunol 1994;24:1941 - 4.

19. Nunokawa Y, Ishida N, Tanaka S. Promoter analysis of human inducible nitric oxide synthase gene associated with cardiovascular homeostasis. Biochem Biophys Res Commun 1994;200:802-7.

20. Chartrain NA, Geller DA, Koty PP, et al. Molecular cloning, structure, and chromosomal localization of the human inducibie nitric oxide synthase gene. J Biol Chem 1994;269:6765-72.

21. MacNaul KL, Hutchinson NI. Differential expression of iNOS and cNOS mRNA in human vascular smooth muscle cells and endothelial cells under normal and inflammatory conditions. Biochem Biophys Res Commun $1993 ; 196: 1330-4$
22. Werner-Felmayer G, Werner ER, Fuchs D, et al. Pteridine biosynthesis in human endothelial cells. Impact on nitric oxide-mediated formation of cyclic GMP. J Biol Chem 1993;268:1842-6.

23. Schaffner A, Blau N, Schneemann M, Steurer J, Edgell C-JS, Schoedon G. Tetrahydrobiopterin as another EDRF in man. Biochem Biophys Res Commun 1994;205:516-23.

24. Ignarro LJ, Byrns RE, Buga GM, Wood KS. Endothelium-derived relaxing factor from pulmonary artery and vein possesses pharmacologic and chemical properties identical to those of nitric oxide radical. Circ Res 1987;61:866-79.

25. Schoedon G, Schneemann M, Blau N, Edgell C-JS, Schaffner A. Modulation of human endothelial cell tetrahydrobiopterin synthesis by activating and deactivating cytokines: new perspectives on endotheliumderived relaxing factor. Biochem Biophys Res Commun 1993; 196: $1343-8$.

26. Schoedon G, Blau N, Schneemann M, Flury G, Schaffner A. Nitric oxide production depends on preceding tetrahydrobiopterin synthesis by endothelial cells: selective suppression of induced nitric oxide production by sepiapterin reductase inhibitors. Biochem Biophys Res Commun 1994; 199:504 10 .

27. Van Amsterdam JGC, Wemer J. Tetrahydrobiopterin induces vasodilatation via enhancement of cGMP level. Eur J Pharmacol 1992;215: $349-50$.

28. Zingarelli B, Carnuccio R, Di Rosa M. Cloricromene inhibits the induction of nitric oxide synthase. Eur J Pharmacol 1993;243:107-11.

29. Cobb JP, Natanson C, Hoffman WD, et al. $\mathrm{N}^{\omega}$-amino-L-arginine, an inhibitor of nitric oxide synthase, raises vascular resistance but increases mortality rates in awake canines challenged with endotoxin. $J$ Exp Med $1992 ; 176: 1175-82$.

30. Ignarro LJ. Haem-dependent activation of guanylate eyclase and cyclic GMP formation by endogenous nitric oxide: a unique transduction mechanism for transcellular signaling. Pharmacol Toxicol 1990; $67: 1-7$ 